\title{
Development and validation of the sleep assessment instrument for older adults with pain
}

\author{
Desenvolvimento e validação do instrumento de avaliação de sono para idosos com dor \\ Márcia Valéria de Andrade SANTANA', Ricardo Humberto FÉLIX', Ana Laura de Figueiredo BERSANI', \\ Cristina FRANGE ${ }^{2}$, Fernando Morgadinho Santos COELHO², Osvladir CUSTÓDIO, Fania Cristina SANTOS ${ }^{1}$
}

\begin{abstract}
Background: The co-occurrence of chronic pain and sleep disturbance contribute to a significant functional and social impact in older adults. However, there are no validated instruments to measure sleep disturbance and pain in this population that could be used to screen or diagnose individuals or monitor treatment effectiveness. Objective: Our aim was to develop and validate a brief, practical, and comprehensive tool to assess the impact of co-occurring pain and sleep disturbance in older adults. Methods: Development and validation of a measurement tool for assessing pain and sleep in older adults consisting of seven items. Results: We applied the "Sleep Assessment Instrument for Pain in older adults" (SAIOAP) in a sample of 100 older individuals. A Cronbach's alpha of 0.602 indicated a moderate level of reliability, and item-total correlations of $\geq 0.4$ for all items indicated good homogeneity. There were statistically significant correlations between the SAIOAP and sleep quality (PSQI, $r=61.5$ ), pain intensity (VNS, $r=30.5)$, the multidimensional impacts of pain (GPM, $r=40.5$ ), depression (GEAP, $r=45.5)$, comorbidity ( $r=27.9)$, and medication use $(r=30.4)$. A ROC curve indicated a sensitivity of $73.2 \%$ and a specificity of $79.1 \%$ in relation to the prediction of sleep disturbances associated with pain in older adults. Conclusions: The SAIOAP presented adequate metric properties and was demonstrated to be a simple and practical tool for the assessment of the impact of pain on sleep in older adults.
\end{abstract}

Keywords: Sleep; Pain; Aged; Surveys and Questionnaires; Health Impact Assessment.

\section{RESUMO}

Introdução: A co-ocorrência de dor crônica e de distúrbios do sono contribuem para um impacto funcional e social negativo em idosos. Porém, o binômio dor-sono não foi explorado em relação a questionários para idosos, a fim de auxiliar na triagem, no diagnóstico ou no monitoramento da eficácia do tratamento médico. Objetivo: Desenvolver e validar um instrumento breve, prático e abrangente para avaliar a concorrência de condições álgicas crônicas e distúrbios de sono em idosos. Métodos: Estudo descritivo e qualitativo de metodologia de desenvolvimento e validação de instrumento de medida para avaliação de dor e sono em idosos, composto por sete itens. Após a fundamentação teórica, desenvolveram-se os itens do instrumento, seguidos de um estudo quantitativo (validação), em que testamos pacientes idosos com dor crônica. Resultados: Aplicou-se o Instrumento de Avaliação de Sono para Dor em Idosos (IASID) a uma amostra de 100 idosos. Alcançou-se o alfa de Cronbach $(0,602)$ de boa homogeneidade por correlação item-total $(\geq 0,4)$. Encontramos correlações estatisticamente significativas entre o IASID e a qualidade do sono (PSQI, $r=61,5 \%$ ); a intensidade da dor (NVS, $r=30,5 \%$ ); seus impactos (GPM, $r=40,5)$; depressão (GEAP, $r=45,5 \%)$; comorbidades $(r=27,9)$ e uso de medicamentos $(r=30,4)$. A curva ROC apontou sensibilidade de $73,2 \%$ e especificidade de 79,1\% para predição de distúrbios do sono associados à dor crônica em idosos. Conclusões: 0 IASID apresentou propriedades métricas adequadas e demonstrou ser uma ferramenta simples e prática para a avaliação do impacto da dor no sono em idosos.

Palavras-chave: Sono; Dor; Idoso; Inquéritos e Questionários; Avaliação do Impacto na Saúde.

\footnotetext{
'Universidade Federal de São Paulo, Departamento de Geriatria e Gerontologia, Serviço de Doenças Musculoesquelentas, São Paulo SP, Brazil.

¿Universidade Federal de São Paulo, Departamento de Neurologia e Neurocirurgia, São Paulo SP, Brazil.

${ }^{3}$ Universidade Federal de São Paulo, Departamento de Psiquiatria, São Paulo SP, Brazil.

MVAS (D) https://orcid.org/0000-0001-9758-6148; RHF (D) https://orcid.org/0000-0001-5854-6418;ALFB (D) https://orcid.org/0000-0002-9563-2291; CF (iD https://orcid.org/0000-0002-5435-3579; FMSC (D) https://orcid.org/0000-0002-8482-3754; OC (iD https://orcid.org/0000-0002-5526-4711; FCS (iD) https://orcid.org/0000-0003-2689-3532

Correspondence: Cristina Frange; Email: cristina.frange15@gmail.com.

Conflict of interests: There is no conflict of interest to declare.
}

Authors' contributions: FCS: conception or design of the study; MVAS, RHF, ALFB: data collection; MVAS, RHF, ALFB, FCS: data analysis and interpretation; MVAS, RHF, ALFB, CF, FCS: drafting the article; CF, FMSC, OC, FCS: critical revision of the article. All authors read and approved the final version of the manuscript for publication.

Support: Cristina Frange receives of a grant from the São Paulo Research Foundation (FAPESP \#2018/18952-1). The sponsor had no role in the design or conduct of this research.

Received on September 23, 2020; Received in its final form on November 18, 2020; Accepted on December 13, 2020. 


\section{INTRODUCTION}

Sleep disorders and chronic pain are two major health issues with high incidence in older adults ${ }^{1,2,3}$. Approximately $40 \%$ of older adults suffer from sleep disturbances causing a reduction in functional status and quality of life, besides being responsible for an increase of clinical and psychiatric comorbidities in this population ${ }^{4}$. Sleep disturbances (or sleep-wake disorders) involve problems with the quality, timing, and amount of sleep, which result in diurnal impairment and distress, and impairment in functioning. Sleep disturbances include sleep-related breathing disorders such as central, obstructive or mixed sleep apnea, insomnia, parasomnias, narcolepsy, REM sleep behavior disorder, excessive sleepiness, circadian rhythm disorders, and restless leg syndrome, amongst more than 80 sleep disturbances. Similarly, chronic pain is a prevalent and extremely debilitating condition, affecting more than $50 \%$ of community-dwelling older individuals and more than $80 \%$ of nursing home residents $^{2,5,6}$. Chronic pain is also a risk factor for premature death and accelerated cognitive decline ${ }^{7}$.

There is a complex bidirectional relationship between chronic pain and sleep disorders, which has important implications for clinical management of older patients ${ }^{8,910}$. It is estimated that 40 to $88 \%$ of the geriatric population has coexistences of both conditions with various etiologies; for instance, migraine, musculoskeletal pain (e.g. chronic low back pain, arthralgia), fibromyalgia, osteoarthritis, and irritable bowel syndrome ${ }^{11,12,13}$. Moreover, both conditions can be predictors of frailty in older adults ${ }^{14}$.

Chronic pain affects sleep in different ways, including increased insomnia, more fragmented sleep, and shorter sleep duration ${ }^{15,16}$. A recently published meta-analysis estimated a pooled prevalence of $44 \%$ of sleep disorders in patients with chronic nonmalignant pain, the most common being insomnia (72\%), restless legs syndrome (32\%), and obstructive sleep apnea $(32 \%)^{17}$. Objective polysomnographic measures in individuals with chronic pain have demonstrated increased sleep onset latency, time awake after sleep onset, number of awakenings, light sleep, number of stage-shifts, respiratory-related events and periodic limb-movements, and diminished sleep efficiency and sleep duration ${ }^{17}$.

Despite the growing evidence of the sleep-pain association, sleep assessments are not routinely made in older patients with chronic pain, a measure that could help to ensure more effective treatment of pain conditions. The assessment of sleep should involve both subjective and objective measures, but this can be complex and is not always feasible. Concerning subjective sleep, there are some assessment tools which have been shown to have reliability and validity such as the Pittsburgh Sleep Quality Index (PSQI) $)^{18}$, the Epworth Sleepiness Scale (ESS) ${ }^{19}$, the Functional Outcomes of Sleep Questionnaire (FOSQ) $)^{20}$, the Insomnia Severity Index (ISI) ${ }^{21}$, the Insomnia Symptom Questionnaire $(\text { ISQ })^{22}$, the Insomnia Impact Scale (IIS) ${ }^{23}$, the Jenkins Sleep Evaluation Questionnaire (JSEQ) ${ }^{24}$, and the Sleep Scale from the Medical Outcomes Study (MOS) $)^{25}$. However, none of these were specifically developed to assess "sleep and pain", and neither are they specific for older adults.

To assess sleep disturbances associated with chronic pain there are very few available tools. Only two of them have been widely used: i) the Pain and Sleep Questionnaire Three-item Index (PSQ-3), a direct measure of the impact of chronic pain on sleep ${ }^{26}$, and ii) the Chronic Pain Sleep Inventory (CPSI), a 5 items tool using a $100 \mathrm{~mm}$ visual analogue scale ${ }^{27}$. However, there is no guidance on which of these existing self-reported sleep-pain measures best capture the aspects of sleep disturbance that are most pertinent to older adults with chronic pain. Moreover, the two assessment tools were designed for the general population and not specifically for the older population. In respect of geriatric patients, the reasons for different types of pain and sleep disturbances are related to changes specifically associated with the aging process. It is important to have a tool that can be easily applied and provide the most comprehensive and detailed assessment of sleep-pain possible.

There is, therefore, a lack of validated measures of sleep disturbances in chronic pain conditions designed specifically for older adults. The creation of such a measure could help in the management of pain in aging, and optimize quality of life and functioning.

\section{METHODS}

The development and validation of the instrument to assess the impact of pain on sleep in older adults involved three steps, following a model previously described by Kline $^{28}$ : (1) the establishment of the theoretical background/ literature review, (2) a qualitative study involving the development of the tool items and the establishment of face validity, and (3) a quantitative study that involved testing the instrument with older adults with chronic pain as part of the validation process.

\section{Ethical aspects}

All procedures performed in studies involving human participants were in accordance with the ethical standards of the institutional and/or national research committee. The study protocol was approved by the Institutional Research Ethics Committee of the Universidade Federal de São Paulo (UNIFESP, CEP \# 072353-2014). This article does not contain any studies with animals performed by any of the authors.

\section{Theoretical evidence and elaboration of the tool items}

Using the process suggested by Kline (1995) for the development of an instrument $t^{28}$, we followed three steps as 
outlined. i) We gathered theoretical evidence through a careful thematic bibliographic review, which served to clarify the nature and range of the content related to the target construct, namely, an instrument to assess pain and sleep disorders in older adults. ii) We elaborated the tool items, taking into consideration the terms and language known to the geriatric population. In this stage, we analyzed some reliable and validated questionnaires related to sleep assessment, some involving assessment of both pain and sleep (PSQI, ESS, MOS, PSQ-3, and CPSI). The tool included seven items, demonstrating "content validity" (proved to be representative of the universe of related content). iii) The tool was then analyzed by a committee of five experts in neurology, psychiatry, gerontology, family medicine, and sleep medicine related to the subject. A minimal consensus by $80 \%$ of the experts was the criterion required to retain an item (face validity). The committee of experts stated that the older population with chronic pain conditions and sleep disturbances is clinically heterogeneous and complex, thus making the management of this entangled relationship (sleep-pain) challenging; the two conditions must be dissociated in clinical practice. Also, medications prescribed to treat pain should not affect sleep, and vice-versa, as sleep disturbances may have an adverse effect on the course of chronic pain conditions in older adults.
This process resulted in the production of the "Sleep Assessment Instrument for Older Adults with Pain” (SAIOAP) (Figure 1) - a tool consisting of seven items with "yes" or "no" answers, grouped according to the broad dimensions of sleep: initiating sleep (item 1), maintaining sleep (items 2 and 3), physical discomfort such as tiredness, exhaustion and fatigue (item 4), self-perception of sleep (item 5), daytime sleepiness (item 6), and medications used to sleep (item 7). In addition, four sub-items related to sleep latency, duration, and efficiency (in items 1 and 2) were also established for a qualitative analysis.

To evaluate the new tool, we carried out a pilot test in a sample of 15 older individuals with chronic pain. The questionnaires were completed by an investigator who read the questions and wrote down the patients' answers. None of the test subjects found any difficulties in answering the questions so no adjustments to the tool were necessary.

\section{Sample size calculation}

The sample size was calculated for $95 \%$ power, an effect size of 0.602 with Cohens' $d$ of 0.50 , and an $\alpha$ error of 0.05 . For the subjective parameters (PSQI, GPM, GEAP, ADLs, and IADLs as outcomes) the required sample size was 44 participants. The sample size calculation was made using $G^{*}$ Power software (version 3.1.9.2, Franz Faul, Utah, USA, www.ncss.com.).

\section{Sleep Assessment Instrument for Older Person with Pain - SAIOAP}

1. Do you take more than 30 minutes to fall asleep due to pain?

\begin{tabular}{|c|c|}
\hline Yes & No \\
\hline
\end{tabular}

During the last month, on typical nights:

A. What time do you usually go to bed?

B. How long does it take you to fall asleep?

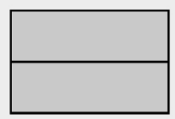

2. Due to pain, do you wake up earlier than you would like to, and have difficulty getting back to sleep? During the last month, on typical nights:

A. What time do you get up in the morning?

B. How much did you sleep?

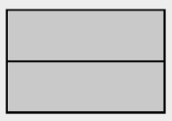

3. Do you wake up in the middle of the night or earlier in the morning due to pain?

\begin{tabular}{|c|c|}
\hline Yes & No \\
\hline
\end{tabular}

\section{Do you still feel tired when you wake up in the morning?}

\begin{tabular}{|c|c|}
\hline Yes & No \\
\hline
\end{tabular}

5. Do you have a bad/very bad perception of your sleep?

\begin{tabular}{l|l} 
Yes & No \\
\hline
\end{tabular}

6. Do you feel sleepy during the day?

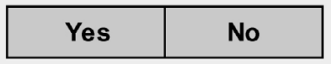

7. Do you take any medication to sleep?

Yes

No

Figure 1. Sleep Assessment Instrument for Older Person with Pain (SAIOAP). 


\section{Validation of Sleep Assessment}

\section{Instrument for Older Person with Pain}

The validation process was also carried out according to the method described by Kline and collaborators ${ }^{28}$ : a) reliability analysis (internal consistency); b) validation; c) standardization of the application (implementing) process, assessment, and interpretation of the tool.

To complete the validation, a sample of 100 individuals was randomly selected from patients undergoing clinical follow up at the Geriatrics and Gerontology Department of the Universidade Federal de São Paulo. These patients complied with the inclusion criteria of being aged 60 years or older and presenting chronic pain ( $\geq 6$ months). Individuals with cancer pain and cognitive impairment were excluded. All participants signed an informed consent form.

A semi-structured questionnaire was used to collect information on socio-demographic data (age, gender, race, marital status and education), self-perception of health, comorbidities, and regularly used medications, including those prescribed for sleep disorder (e.g., benzodiazepines and " $z$ drugs", such as Zolpidem). Based on the medication information, we classified the participants according to the number of drugs regularly used, and defined polypharmacy as the use of 5 to 9 different drugs, and excessive polypharmacy as the use of $\geq 10$ different drugs.

Functional capacity was assessed using the Katz activities of daily living (ADLs) scale ${ }^{28}$ to evaluate the abilities to undertake activities such as feeding, bathing, dressing, and leisure. The Lawton instrumental activities of daily living (IADLs) scale ${ }^{29}$ was used to evaluate activities that are not necessary for fundamental functioning, but important for independent living, such as cleaning and maintaining the house and managing money. In addition, information was collected on self-perception of health status and categorized as excellent, good, regular, and poor.

The multidimensional aspects of pain were evaluated, including duration, frequency, intensity, localization, affectivity, functional impact, and others. The verbal numerical scale (VNS) of pain was applied to assess the intensity of pain ${ }^{30}$ and the geriatric pain measure (GPM) was applied to assess the multidimensional aspects through domains of pain (sensorydiscriminative, motivational-affective, and cognitive evaluative $)^{31}$. According to the physiopathogenesis, pain was classified as nociceptive, neuropathic, or mixed, and according to its localization, as muscle, joint, nerve, or other pain.

To assess affectivity, an important aspect related to pain, we used the Geriatric Emotional Assessment of Pain (GEAP), which indicates little or no pain-induced depression (scores 0 to 5), moderate pain-induced depression (scores 6 to 9), and severe pain-induced depression (scores $\geq 10$ ) ) $^{32,33}$. For the subjective assessment of sleep, we used the Brazil Portuguese version of the PSQI, which assesses sleep quality with a sensitivity of approximately $80 \%$ and specificity of approximately $68.8 \%^{18}$.
Lastly, the participants were asked to answer the items of SAIOAP; we established a standard method of application to ensure uniformity in the use of the instrument.

\section{Statistical data analysis}

Data were analyzed by means of descriptive and parametric statistics using Statistical Package for the Social Sciences version 17 (SPSS Inc. Released 2008. SPSS Statistics for Windows, Version 17.0. Chicago: SPSS Inc.), Minitab 16 (Minitab 16 Statistical Software 2010. Computer software. State College, PA: Minitab, Inc. (www.minitab.com)), and Microsoft Excel (Microsoft Corporation, 2010). To evaluate the internal consistency of the instrument, Cronbach's alpha and total-item correlation were calculated. The associations between SAIOAP and PSQI, GPM, GEAP, ENV, comorbidity, and medication were analyzed using Pearson's correlation coefficient, and those associations related to quantitative variables, such as age range, functionality, pain characterization, self-perception of health, comorbidity, medication, GEAP, and PSQI were analyzed using the analysis of variance test (ANOVA). The Receiver Operating Characteristic (ROC) methodology was used to assess the ability of SAIOAP to predict pain in older adults with sleep disturbance. Significance was defined as $\mathrm{p}<0.05$.

\section{RESULTS}

The development process described above resulted in the production of a final instrument that could be easily understood by the participants. It was very easy to apply, taking approximately five minutes.

A sample of 100 older adults with an average age of 83.1 years old and that was predominantly female $(86.9 \%)$ was used in the validation process. The data from baseline measurements are shown in Table 1.

We analyzed the internal consistency of SAIOAP to test its reliability. The Cronbach's alpha for the whole instrument was 0.602 , indicating a moderate level of reliability (Table 2). The total-item correlation showed that all values had a score higher than 0.4 , indicating good homogeneity between the items of the SAIOAP (suggesting that it was not necessary to delete any items) (Table 2).

We observed statistically significant correlations between the SAIOAP and sleep quality, pain (both in respect of intensity and multidimensional aspects), independence in respect of ADLs, comorbidity, medication consumption, and depression (Table 3). The strongest correlation observed was with sleep quality $(\mathrm{r}=68.3 \%$; $\mathrm{p}<0.001)$, indicating convergent construct validity of the SAIOAP.

The ROC curve analysis with the PSQI demonstrated that the SAIOAP had sensitivity of $73.2 \%$ and specificity of $79.1 \%$ (with an area under the curve of $0.798, \mathrm{p}=0.046$ ). The best cutoff point found for the SAIOAP was 1.5, therefore, two or 
Table 1. Summary of the main characteristics of the participants $(n=100)$

\begin{tabular}{|c|c|c|c|c|}
\hline \multicolumn{2}{|c|}{ Qualitative variables } & \multirow{2}{*}{$\frac{n}{3}$} & \multirow{2}{*}{$\begin{array}{l}\% \\
3.0\end{array}$} & \multirow{2}{*}{$\frac{p \text {-value }}{<0.001}$} \\
\hline \multirow{3}{*}{ Age (years) } & $60-69$ & & & \\
\hline & $70-79$ & 24 & 24.2 & $<0.001$ \\
\hline & $\geq 80$ & 72 & 72.2 & Ref. \\
\hline \multirow{2}{*}{ Gender } & Female & 86 & 86.9 & $<0.001$ \\
\hline & Male & 13 & 13.1 & Ref \\
\hline \multirow{4}{*}{ Race } & Black & 13 & 13.1 & $<0.001$ \\
\hline & White & 59 & 59.6 & Ref. \\
\hline & Brown & 26 & 26.3 & $<0.001$ \\
\hline & Asian & 1 & 1.0 & $<0.001$ \\
\hline \multirow{4}{*}{ Marital status } & Married & 30 & 30.3 & $<0.001$ \\
\hline & $\begin{array}{l}\text { Separated/ } \\
\text { divorced }\end{array}$ & 7 & 7.1 & $<0.001$ \\
\hline & Widowed & 54 & 54.5 & Ref. \\
\hline & Single & 8 & 8.1 & $<0.001$ \\
\hline \multirow{3}{*}{ ADLs } & $1-2$ & 1 & 1.0 & $<0.001$ \\
\hline & $3-4$ & 4 & 4.0 & $<0.001$ \\
\hline & $5-6$ & 94 & 94.9 & Ref. \\
\hline \multirow{4}{*}{ IADLs } & $09-15$ & 6 & 6.1 & $<0.001$ \\
\hline & $16-20$ & 14 & 14.1 & $<0.001$ \\
\hline & $21-25$ & 30 & 30.3 & 0.006 \\
\hline & $26-27$ & 49 & 49.5 & Ref. \\
\hline \multirow{4}{*}{$\begin{array}{l}\text { Self- } \\
\text { perception } \\
\text { of health }\end{array}$} & Excellent & 5 & 5.1 & $<0.001$ \\
\hline & Good & 26 & 26.3 & $<0.001$ \\
\hline & Regular & 61 & 27.3 & Ref. \\
\hline & Poor & 7 & 7.1 & $<0.001$ \\
\hline \multirow{3}{*}{ Polypharmacy } & No polypharmacy & 20 & 20.2 & $<0.001$ \\
\hline & Polypharmacy & 52 & 52.5 & Ref. \\
\hline & $\begin{array}{c}\text { Severe } \\
\text { polypharmacy }\end{array}$ & 27 & 27.3 & $<0.001$ \\
\hline \multirow{3}{*}{ Pain type } & Nociceptive & 77 & 77.8 & Ref. \\
\hline & Neuropathic & 7 & 7.1 & $<0.001$ \\
\hline & Mixed & 15 & 15.2 & $<0.001$ \\
\hline \multirow{3}{*}{ Pain frequency } & Continuous & 46 & 46.5 & Ref. \\
\hline & Intermittent & 45 & 45.5 & 0.887 \\
\hline & Occasional & 8 & 8.1 & $<0.001$ \\
\hline \multirow{4}{*}{$\begin{array}{l}\text { Pain } \\
\text { localization }\end{array}$} & Muscle & 26 & 26.3 & $<0.001$ \\
\hline & Joint & 82 & 82.8 & Ref. \\
\hline & Nerve & 20 & 20.2 & $<0.001$ \\
\hline & Others & 2 & 2 & $<0.001$ \\
\hline \multirow{3}{*}{$\begin{array}{l}\text { Pain intensity } \\
\text { (VNS) }\end{array}$} & Mild & 4 & 4.0 & $<0.001$ \\
\hline & Moderate & 36 & 36.4 & $<0.001$ \\
\hline & Severe & 59 & 59.6 & Ref. \\
\hline \multirow{3}{*}{ Pain by GPM } & Mild & 7 & 7.1 & $<0.001$ \\
\hline & Moderate & 60 & 60.6 & Ref \\
\hline & Severe & 32 & 32.3 & $<0.001$ \\
\hline
\end{tabular}

Continue...
Table 1. Continuation.

\begin{tabular}{|c|c|c|c|c|}
\hline \multicolumn{2}{|c|}{ Qualitative variables } & \multirow{2}{*}{$\frac{n}{43}$} & \multirow{2}{*}{$\begin{array}{c}\% \\
43.4\end{array}$} & \multirow{2}{*}{$\begin{array}{c}\text { p-value } \\
\text { Ref }\end{array}$} \\
\hline \multirow{3}{*}{ GEAP } & $\begin{array}{l}\text { No or mild } \\
\text { depression }\end{array}$ & & & \\
\hline & $\begin{array}{l}\text { Moderate } \\
\text { depression }\end{array}$ & 37 & 37.4 & 0.385 \\
\hline & $\begin{array}{c}\text { Severe } \\
\text { depression }\end{array}$ & 19 & 19.2 & $<0.001$ \\
\hline \multirow{2}{*}{ PSQI } & Good sleeper & 43 & 43.4 & 0.065 \\
\hline & Poor sleeper & 56 & 56.6 & Ref. \\
\hline \multicolumn{2}{|c|}{ Quantitative variables } & Mean & SD & Range \\
\hline \multicolumn{2}{|c|}{ Age (years) } & 83.13 & \pm 7.21 & $64-98$ \\
\hline \multicolumn{2}{|c|}{ Education (years) } & 3.84 & \pm 3.14 & $0-15$ \\
\hline \multicolumn{2}{|c|}{ Comorbidity (number) } & 5.71 & \pm 2.29 & $2-11$ \\
\hline \multicolumn{2}{|c|}{ Medication (number) } & 7.93 & \pm 3.04 & $2-14$ \\
\hline \multicolumn{2}{|c|}{ Pain duration (months) } & 9.15 & \pm 9.74 & $0.25-50$ \\
\hline \multicolumn{2}{|c|}{ Pain intensity (VNS) } & 7.10 & \pm 1.95 & $3-10$ \\
\hline \multicolumn{2}{|c|}{ Pain by GPM } & 61.40 & \pm 19.41 & $4.7-99.9$ \\
\hline \multicolumn{2}{|l|}{ GEAP } & 6.86 & \pm 4.59 & $0-21$ \\
\hline \multicolumn{2}{|l|}{ PSQI } & 6.54 & \pm 3.93 & $1-18$ \\
\hline \multicolumn{2}{|c|}{ SAIOAP } & 1.96 & \pm 1.55 & $1-7$ \\
\hline
\end{tabular}

ADLs: activities of daily living; IADLs: instrumental everyday activities; SD: standard deviation; VNS: verbal numeric scale; GPM: geriatric pain measure; GEAP: Geriatric Emotional Assessment of Pain; PSQI: Pittsburgh Sleep Questionnaire Index; SAIOAP: Sleep Assessment Instrument for Older Person with Pain

Table 2. Internal consistency of Sleep Assessment Instrument for Older Person with Pain (SAIOAP) measure with Cronbach alpha and corrected total-item correlation.

\begin{tabular}{lc}
\hline SAIOAP & Corrected total-item correlation \\
\hline Item 1 & 0.520 \\
Item 2 & 0.533 \\
\hline Item 3 & 0.589 \\
Item 4 & 0.580 \\
Item 5 & 0.496 \\
Item 6 & 0.613 \\
Item 7 & 0.598 \\
Cronbach alpha (Total) & 0.602 \\
\hline
\end{tabular}

SAIOAP: Sleep Assessment Instrument for Older Person with Pain.

Table 3. Correlation between Sleep Assessment Instrument for Older Person with Pain (SAIOAP) and principal variables by Pearson's correlation.

\begin{tabular}{lcc}
\hline & Correlation ( $r$ ) & p-value \\
\hline Sleep quality (PSQI) & $68.3 \%$ & $<0.001$ \\
Pain intensity (VNS) & $28.5 \%$ & 0.004 \\
\hline $\begin{array}{l}\text { Multidimensional aspects of } \\
\text { pain (GPM) }\end{array}$ & $40.5 \%$ & $<0.001$ \\
Depression (GEAP) & $46.1 \%$ & $<0.001$ \\
Comorbidity (number) & $28.2 \%$ & 0.005 \\
Medication (number) & $32.6 \%$ & 0.001 \\
\hline
\end{tabular}

PSQI: Pittsburgh Sleep Quality Index; VNS: verbal numeric scale; GPM: geriatric pain measure; GEAP: geriatric emotional of pain. 
more scores from the SAIOAP could produce a total score that predicted sleep disturbances in older adults with pain (Figure 2).

\section{DISCUSSION}

In the current study we developed and validated an assessment tool designed specifically for older adults with chronic pain. This is the first instrument designed to measure the pain-sleep relationship in this population. The SAIOAP is quick and easy to apply, and considers important sleep dimensions, namely, sleep onset and maintenance, physical discomfort, diurnal repercussions of sleep such as excessive daytime sleepiness, self-perception of health status, and medication used for sleep. The SAIOAP was applied in a sample of older adults whose pain intensity was mainly moderate or severe, and the average duration of experiencing pain was about nine years. In addition, the participants frequently presented pain-induced depression

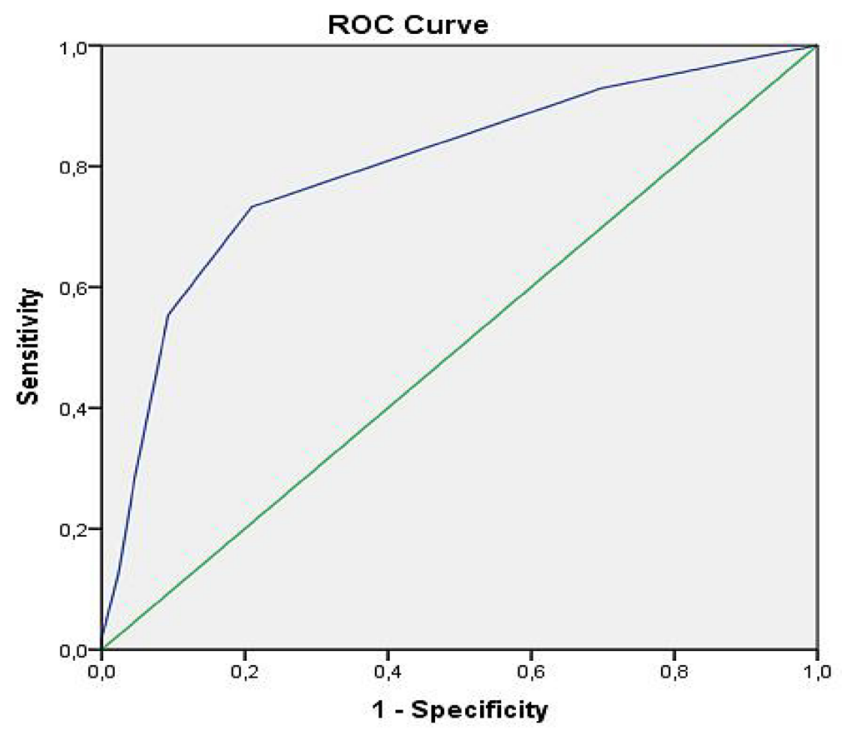

Diagonal segments are produced by ties

\begin{tabular}{|lcc|}
\hline \multicolumn{3}{c}{ SAIOAP - Sensitivity and specificity } \\
\hline PSQI & Sensitivity & Specificity \\
\hline-1.0 & $100.0 \%$ & $0.0 \%$ \\
\hline 0.5 & $92.9 \%$ & $30.2 \%$ \\
\hline 1.5 & $73.2 \%$ & $79.1 \%$ \\
\hline 2.5 & $55.4 \%$ & $90.7 \%$ \\
3.5 & $28.6 \%$ & $95.3 \%$ \\
\hline 4.5 & $12.5 \%$ & $97.7 \%$ \\
\hline 5.5 & $1.8 \%$ & $100.0 \%$ \\
7.0 & $0.0 \%$ & $100.0 \%$ \\
\hline
\end{tabular}

Figure 2. ROC curve for the performance of the Sleep Assessment Instrument for Older Person with Pain (SAIOAP) according to the Pittsburgh Sleep Questionnaire Index. (more than $50 \%$ of the sample), which suggests that pain had an important affective impact in our sample. The presence of an intrinsic relationship between pain and depression is significant, and both conditions should be simultaneously treated ${ }^{17}$. This is in line with the suggestion by some authors that sleep problems need to be considered in a broader context $\mathrm{t}^{25}$.

We observed adequate psychometric proprieties for the SAIOAP. Foremost, content and face validity were demonstrated, respectively, by including universally representative content and by experts assessing if the content looked appropriate "on the face of it" (face validity). The other psychometric properties of the SAIOAP were shown to be good. The Cronbach's alpha did not reach 0.7 , which is generally considered the cut off for good internal consistency, and this may be related to the small number of items in the instrument. All items in the scale had scores above 0.4 which indicated very good discriminant validity ${ }^{34}$. Nevertheless, the total-item correlation indicated that the assessment tool had uniform items (values all above 0.4). That is, all 7 items had moderate correlation with SAIOAP total scores ${ }^{35}$. In the validation process, a statistically significant correlation was verified between the SAIOAP and several factors, particularly sleep quality (PSQI). There was also a statistically significant and positive association of SAIOAP with the uni- and multidimensional aspects of pain, pain-induced depression, comorbidities, number of medications used, and self-perception of health. The correlation with sleep quality determined the construct validity of the SAIOAP.

Our finding that sleep quality in our sample was considered poor is in accordance with the literature. Older adults tend to present poor sleep quality, with studies in the literature showing that rates of sleep disorders elderlies with pain range from 40 to $88 \% \%^{36,37}$. However, poor quality of sleep is not found in all older adults, and it should not be assumed to be "a normal finding". There are many highly functional older adults that have a restorative sleep, even though it is often of objectively poorer quality compared with younger adults $^{38,39}$. In addition, in older adults there may be agerelated sleep changes such as changes in circadian rhythm (phase advance) and sleep architecture changes (e.g., shortened sleep duration, frequent awakenings, and decreased slow wave sleep). Furthermore, an increased frequency of daytime naps and time spent awake during the night could also negatively influence sleep. A lack of physical activity and sedentary behavior could also predispose individuals to more pain, increased pain perception, and reduced sleep consolidation. Contrary, pain might also predispose individuals to less activity and sedentary behavior. Therefore, although sleep disorders have multifactorial causes, sleep disorders in older adults are often attributed to pain ${ }^{3}$. Again, the homeostatic mechanisms of sleep become less robust with normal aging and added to changes in hormone secretion profiles can negatively impact the sleep-pain relationship ${ }^{38,39}$. 
Sleep disturbance is a crucial component in the conceptual model for sleep-related problems in patients with pain. The SAIOAP was shown to have both sensitivity and specificity in relation to predicting pain in older adults with sleep disturbance, thus this tool can be used in clinical practice to screen, diagnose, and monitor the painsleep relationship in this specific clinical population and evaluate the effectiveness of treatments.

There are some limitations to be considered. Sleep analysis could be better determined using objective polysomnographic or actigraphy examination, but this was not possible due to the high cost and was not therefore included in the analysis. In addition, other factors such as reproducibility and predictive validity were not fully explored and will require further investigation.
The results of the present study show that the SAIOAP should be used as a direct measure of the impact of sleep in older patients with pain. This is an easy-to-apply, detailed assessment tool for the pain-sleep relationship in the older population, and the study has shown the tool to be a reliable and valid for the screening of sleep disturbances in older adults with pain. This tool could be used to identify older adults with sleep disturbances and pain, facilitating prompt targeted treatment in relation to both conditions.

The SAIOAP is an easy and short tool for researchers and health professionals to directly evaluate the impact of co-occurring pain and sleep disturbance on older adults, something that is not possible with the few currently validated measures.

\section{References}

1. Neikrug AB, Ancoli-Israel S. Sleep disorders in the older adult - a mini-review. Gerontology. 2010 Mar;56(2):181-9. https://doi. org/10.1159/000236900

2. Helme RD, Gibson SJ. The epidemiology of pain in elderly people. Clin Geriatr Med. 2001 Aug;17(3):417-31. https://doi.org/10.1016/s07490690(05)70078-1

3. Dentino A, Medina R, Steinberg E. Pain in the elderly: identification, evaluation, and management of older adults with pain complaints and pain-related symptoms. Prim Care. 2017 Sep;44(3):519-28. https://doi.org/10.1016/j.pop.2017.04.009.

4. Chen Q, Hayman LL, Shmerling RH, Bean JF, Leveille SG. Characteristics of chronic pain associated with sleep difficulty in older adults: the Maintenance of Balance, Independent Living, Intellect, and Zest in the Elderly (MOBILIZE) Boston study. J Am Geriatr Soc. 2011 Aug;59(8):1385-92. https://doi.org/10.1111/j.15325415.2011.03544.X

5. McCarthy LH, Bigal ME, Katz M, Derby C, Lipton RB. Chronic pain and obesity in elderly people: results from the Einstein aging study. J Am Geriatr Soc. 2009 Jan;57(1):115-9. https://doi.org/10.1111/j.15325415.2008.02089.x

6. Apinis C, Tousignant M, Arcand M, Yannick Tousignant Laflamme Y. Can adding a standardized observational tool to interdisciplinary evaluation enhance the detection of pain in older adults with cognitive impairments? Pain Med. 2014 Jan;15(1):32-41. https://doi. org/10.1111/pme.12297

7. Domenichiello AF, Ramsden CE. The silent epidemic of chronic pain in older adults. Prog Neuropsychopharmacol Biol Psychiatry. 2019 Jul;93:284-90. https://doi.org/10.1016/j.pnpbp.2019.04.006

8. Finan PH, Goodin BR, Smith MT. The association of sleep and pain: an update and a path forward. J Pain. 2013 Dec;14(12):1539-52. https:// doi.org/10.1016/j.jpain.2013.08.007

9. Andersen ML, Araujo P, Frange C, Tufik S. Sleep disturbance and pain: a tale of two common problems. Chest. 2018 Nov;154(5):1249-59. https://doi.org/10.1016/j.chest.2018.07.019

10. Mathias JL, Cant ML, Burke ALJ. Sleep disturbances and sleep disorders in adults living with chronic pain: a meta-analysis. Sleep Med. 2018 Dec;52:198-210. https://doi.org/10.1016/j. sleep.2018.05.023

11. Eslami V, Zimmerman ME, Grewal T, Katz M, Lipton RB. Pain grade and sleep disturbance in older adults: evaluation the role of pain, and stress for depressed and non-depressed individuals. Int J
Geriatr Psychiatry. 2016 May;31(5):450-7. https://doi.org/10.1002/ gps.4349

12. Blyth FM, Noguchi N. Chronic musculoskeletal pain and its impact on older people. Best Pract Res Clin Rheumatol. 2017 Apr;31(2):160-8. https://doi.org/10.1016/j.berh.2017.10.004

13. Onen SH, Onen F. Chronic medical conditions and sleep in the older adult. Sleep Med Clin. 2018 Mar;13(1):71-79. https://doi. org/10.1016/j.jsmc.2017.09.007

14. Sodhi JK, Karmarkar A, Raji M, Markides KS, Ottenbacher KJ, Al Snih S. Pain as a predictor of frailty over time among older Mexican Americans. Pain. 2020 Jan;161(1):109-13. https://doi.org/10.1097/j. pain. 0000000000001711

15. Mallon L, Hetta J. A survey of sleep habits and sleeping difficulties in an elderly Swedish population. Ups J Med Sci. 1997;102(3):185-97. https://doi.org/10.3109/03009739709178940

16. Paixão $\mathrm{CM}$, Reichenheim ME. Uma revisão sobre instrumentos de avaliação do estado funcional do idoso. Cad Saude Publica. 2005 Feb;21(1):7-19. https://doi.org/10.1590/S0102-311X2005000100002

17. Mathias JL, Cant ML, Burke ALJ. Sleep disturbances and sleep disorders in adults living with chronic pain: a meta-analysis. Sleep Med. 2018 Dec;52:198-210. https://doi.org/10.1016/j. sleep.2018.05.023

18. Bertolazi AN, Fagondes SC, Hoff LS, Dartora EG, da Silva Miozzo IC, de Barba ME, et al. Validation of the Brazilian Portuguese version of the Pittsburgh Sleep Quality Index. Sleep Med. 2011 Jan;12(1):70-5. https://doi.org/10.1016/j.sleep.2010.04.020

19. Johns MW. A new method for measuring daytime sleepiness: The Epworth sleepiness scale. Sleep. 1991 Dec;14(6):540-5. https://doi. org/10.1093/sleep/14.6.540

20. Weaver TE, Laizner AM, Evans LK, Maislin G, Chugh DK, Lyon K, et al. An instrument to measure functional status outcomes for disorders of excessive sleepiness. Sleep. 1997 Oct;20(10):835-43.

21. Morin CM, Kowatch RA, Wade JB. Behavioral management of sleep disturbances secondary to chronic pain. J Behav Ther Exp Psychiatry. 1989 Dec;20(4):295-302. https://doi.org/10.1016/00057916(89)90060-8

22. Morin CM, Gibson D, Wade J. Self-reported sleep and mood disturbance in chronic pain patients. Clin J Pain. 1998 Dec;14(4):3114. https://doi.org/10.1097/00002508-199812000-00007

23. Zammit GK, WeinerJ, Damato N, Sillup GP, McMillan CA. Quality of life in people with insomnia. Sleep. 1999;22(Suppl 2):5379-85. 
24. Ford DE, Kamerow DB. Epidemiologic study of sleep disturbances and psychiatric disorders. An opportunity for prevention? JAMA. 1989 Sep 15;262(11):1479-84. https://doi.org/10.1001/jama.262.11.1479

25. RAND Health. Sleep scale from the Medical Outcomes Study. 1986 [accessed on Jan 11, 2020]. Available from: http://www.rand.org/ health/surveys_tools/mos/mos_sleep_survey.pdf.

26. LE Ayearst, Z Harsanyi, KJ Michalko. The Pain and Sleep Questionnaire three-item index (PSQ-3): A reliable and valid measure of the impact of pain on sleep in chronic nonmalignant pain of various etiologies. Pain Res Manag. 2012 Jul-Aug;17(4):281-90. https://doi.org/10.1155/2012/635967

27. Kosinski M, Janagap CC, Gajria K, Schein J. Psychometric testing and validation of the chronic pain sleep inventory. Clin Ther. 2007;29 Suppl:2562-77. https://doi.org/10.1016/j.clinthera.2007.12.001

28. Kline P. The handbook of psychological testing. London: Routledge; 1995.

29. Katz S. Assessing self-maintenance: activities of daily living, mobility, and instrumental activities of daily living. J Am Geriatr Soc. 1983 Dec;31(12):721-7. https://doi.org/10.1111/j.1532-5415.1983. tb03391.x

30. Lawton MP, Brody EM. Assessment of older people: self-maintaining and instrumental activities of daily living. Gerontologist. 1969 Autumn;9(3):179-86.

31. Melzack R, Katz R. Pain measurement in persons in pain. In: Wall PD, Melzack R, editors. Textbook of Pain. Edinburgh: Churchill Livingstone; 1999. p. 409-26.
32. Motta TS, Gambaro RC, Santos FC. Mensuração da dor em idosos: avaliação das propriedades psicométricas da versão em português do "Geriatric Pain Measure". Rev Dor. 2015 Jan-Mar;16(2):136-41. https://doi.org/10.5935/1806-0013.20150026

33. Almeida CBL, Felix RH, Cendoroglo MS, Santos FC. Depressão dor-induzida em idosos: validação das propriedades psicométricas da versão brasileira do "Geriatric Emotional Assessment of Pain". Rev Assoc Med Bras. 2017 Sep;63(9):741-6. https://doi. org/10.1590/1806-9282.63.09.741

34. Sneed J, Herman CM. Influence of job characteristics and organizational commitment on job satisfaction of hospital foodservice employees. J Am Diet Assoc. 1990 Aug;90(8):1072-6.

35. Loiacono ET, Watson RT, Goodhue DL. WebQual: Webqual: a web site quality instrument. Working paper 2000-126-0, University of Georgia, Athens, GA; 2000.

36. Pilowsky I, Crettenden I, Townley M. Sleep disturbance in pain clinic patients. Pain. 1985 Sep;23(1):27-33. https://doi.org/10.1016/03043959(85)90227-1

37. Tang NKY, Wright KJ, Salkovski PM. Prevelance and correlates of clinical insomnia co-occuring with chronic back pain. J Sleep Res. 2007 Mar;16(1):85-95. https://doi.org/10.1111/j.13652869.2007.00571.x

38. Vitiello MV. Sleep in normal aging. Sleep Med Clin. 2012 Sep;7(3):539-44. https://doi.org/10.1016/j.jsmc.2012.06.007

39. Li J, Vitiello MV, Gooneratne NS. Sleep in normal aging. Sleep Med Clin. 2018 Mar;13(1):1-11. https://doi.org/10.1016/j.jsmc.2017.09.001 